\title{
18-Fluorodeoxyglucose Positron Emission Tomography and Pancreatic Cancer
}

\author{
Sergio Pedrazzoli ${ }^{a}$ Claudio Pasquali ${ }^{a}$ Cosimo Sperti ${ }^{a}$ Franca Chierichetti ${ }^{b}$ \\ ${ }^{a}$ Department of Medical and Surgical Sciences, IV Surgical Clinic, University of Padova, Padova, and \\ ${ }^{\mathrm{b}}$ Nuclear Medicine Service, PET Centre, Castelfranco Veneto Hospital, Castelfranco Veneto, Italy
}

\section{Dear Sir,}

We read with interest the paper of Lytras et al. [1] on the role of computed tomography (CT) and positron emission tomography (PET) in pancreatic cancer. We believe that the conclusions of the paper should be considered cautiously because of several procedure- and instrumentation-related problems.

The positiveness of fluorodeoxyglucose (FDG)-PET in pancreatic cancer is based on the high constitutive glucose uptake and metabolism that are characteristic features of cancer cells [2]. The glucose transporter-1 (GLUT-1) is a member of the GLUT family of facilitative glucose transporters that mediate $\mathrm{Na}^{+}$-independent cellular uptake of glucose. GLUT-1 has been reported to be over-expressed in a wide range of human cancers, including pancreatic cancer [3]. Tumoral GLUT-1 expression levels are inversely correlated with prognosis; furthermore GLUT-1 promotes invasive and metastatic potential of pancreatic cancer cell lines [3]. We can assume that less aggressive cancers may be false-negative at FDG-PET scan just because of lower levels of GLUT-1 in cancer cells, or because the desmoplastic reaction, typical of pancreatic cancer, reduces the number of cancer cells per square centimeter within the tumor area. It is known that FDG uptake in most malignant tissues increases with time even after $1 \mathrm{~h}$ post injection, while that of benign lesions decreases with time [4]. Both glucose and FDG are used avidly by cellular mediators of inflammation, and false-posi- tive findings in the face of inflammatory changes in the pancreas have been reported [5]. A normal serum concentration of C-reactive protein, a normal leukocyte count and a normal concentration of alkaline phosphatase can help to exclude inflammatory changes [6]. Therefore the interpretation of FDG-PET can be influenced by differences of the procedure and/or of the instrumentation.

First of all it is well known that low standardized uptake values (SUVs) and falsenegative FDG-PET scans have been found in hyperglycemic diabetic patients [5-10], with a decrease in sensitivity for the procedure of about 4\% [9]. To optimize the results of FDG-PET, blood glucose (BG) levels should be checked and found below $130 \mathrm{mg} / \mathrm{dl}$. A 'modified SUV' was also introduced to try to overcome this problem in patients with BG >130 mg/dl [7]. In Lytras et al.'s [1] paper, 10 patients with BG concentrations $>10 \mathrm{mmol} / 1(180.2 \mathrm{mg} / \mathrm{dl})$ were excluded from the comparative analysis, a limit much higher than $130 \mathrm{mg} / \mathrm{dl}$ (7.2 $\mathrm{mmol} / \mathrm{l})$ suggested by most authors [5-9]. Furthermore, the number of patients with BG levels between 130 and $180 \mathrm{mg} / \mathrm{dl}$ was not reported, and no attempt was made to calculate the 'modified SUV'.

The scan acquisition time is also important for the accuracy of the procedure. Image interpretation in FDG-PET is usually performed for images obtained $1 \mathrm{~h}$ post FDG injection [7, 8, 10]. Nakamoto et al. [4] found no significant differences in detec- tion performance of primary tumor between images acquired 1 and $2 \mathrm{~h}$ after FDG injection, but the certainty of excluding liver metastases was increased when the 2hour image was used. In Lytras et al.'s [1] study, scanning started $15 \mathrm{~min}$ after FDG injection and continued for $40 \mathrm{~min}$ (instead of the usual $10 \mathrm{~min}$ acquisition time). This means that scanning started much earlier than generally used, and continued for a quite long time, by this way contributing to a decrease in the accuracy of the procedure.

The interpretation of images obtained with an FDG-PET scan is also crucial. The visual interpretation, as used in the Lytras' study, is not the best one. Visual analysis is reader dependent and less sensitive than SUV. In the study of Koyama et al. [11], the sensitivity and specificity were 82 and $81 \%$ for visual and 93 and $80 \%$ for quantitative (SUV) interpretation. Also the use of semiquantitative analysis methods such as SUV is not yet clearly defined to differentiate malignant from benign pancreatic lesions; a cut-off value of SUV valid for all centers cannot be defined due to the high variability of absolute SUV values among different institutions [12]. However, it is still the most frequently used and reliable method for the interpretation of images obtained with FDG-PET scan.

The choice of instrumentation is of outstanding value for the optimization of the results. The evolution of PET detectors to PET scanners and the progressive improve-

\section{KARGER}

Fax +4161306 1234 E-Mail karger@karger.ch www.karger.com
(C) 2005 S. Karger AG, Basel 0253-4886/05/0226-0467\$22.00/0

Accessible online at:

www.karger.com/dsu
Prof. Sergio Pedrazzoli, MD, FACS, Professor and Chairman

Clinica Chirurgica IV, Dipartimento di Scienze Mediche e Chirurgiche

Via Giustiniani, 2

IT-35128, Padova (Italy)

Tel. +39049821 8827, Fax +39049821 8829, E-Mail sergio.pedrazzoli@unipd.it 
ment of the physical performance of commercial PET scanners [13] render obsolete the results obtained with old instrumentations, like the coincidence detection of gamma-cameras used by Lytras et al. [1]. In oncology, this technique means low resolution and poor detection efficiency.

In conclusion, preoperative diagnosis of pancreatic cancer is useful to reduce the number of aborted resections by less aggressive surgeons, with subsequent reoperative pancreatoduodenectomy in referral centers, and to reduce the rate of inadvertent resections of benign disease by less experienced surgeons [5]. Among newer imaging modalities aimed to avoid these inadequate treatments, 18-FDG-PET is believed by several authors to have an important role in the diagnosis $[5,10]$ and prognosis [8] while others require further evaluation [9]. A consensus conference in Germany concluded that FDG-PET had achieved an established clinical role in the diagnosis and staging of pancreatic cancer [6]. We believe that the conclusions drawn by Lytras et al. [1] on the basis of the comparison between an up-todate CT and a FDG-PET with several procedure and instrumentation bias should be regarded cautiously, especially considering the opposite results and conclusions of a recent paper from Zurich using a last-generation PET-CT [14].

\section{References}

1 Lytras D, Connor S, Bosonnet L, Jayan R, Evans J, Hughes M, Garvey CJ, Ghaneh P, Sutton R, Vinjamuri S, Neoptolemos JP: Positron emission tomography does not add to computed tomography for the diagnosis and staging of pancreatic cancer. Dig Surg 2005;22:55-62.

2 Isselbacher KJ: Sugar and amino acid transport by cells in culture - differences between normal and malignant cells. N Engl $\mathrm{J}$ Med 1972;286:929-933.

3 Ito H, Duxbury M, Zinner MJ, Ashley SW, Whang EE: Glucose transporter-1 gene expression is associated with pancreatic cancer invasiveness and MMP-2 activity. Surgery 2004; 136:548-556.

4 Nakamoto Y, Saga T, Higashi T, Ishimori T, Kobayashi H, Ishizu K, Sato N, Mamede M, Sakahara H, Imamura M, Konishi J: Optimal scan time for evaluating pancreatic disease with positron emission tomography using $\mathrm{F}$ 18-fluorodeoxyglucose. Ann Nucl Med 2003; 17:421-426.

5 Delbeke D: Oncological applications of FDG PET imaging. J Nucl Med 1999;40:17061715.

6 Reske SN, Kotzerke J: FDG-PET for clinical use. Results of the 3rd German Interdisciplinary Consensus Conference, 'Onko-PET III', 21 July and 19 September 2000. Eur J Nucl Med 2001:28:1707-1723

7 Diederichs CG, Staib L, Glatting G, Beger HG, Reske SN: FDG PET: elevated plasma glucose reduces both uptake and detection rate of pancreatic malignancies. J Nucl Med 1998;39: 1030-1033.
8 Sperti C, Pasquali C, Chierichetti F, Ferronato A, Decet G, Pedrazzoli S: 18-Fluorodeoxyglucose positron emission tomography in predicting survival of patients with pancreatic carcinoma. J Gastrointest Surg 2003; 7:953-960.

9 Orlando LA, Kulasingam SL, Matchar DB: Meta-analysis: the detection of pancreatic malignancy with positron emission tomography. Aliment Pharmacol Ther 2004;20:10631070.

10 Van Kouwen MCA, Jansen JB, van Goor H, de Castro S, Oyen WJ, Drenth JP: FDG-PET is able to detect pancreatic carcinoma in chronic pancreatitis. Eur J Nucl Med Mol Imaging 2005;32:399-404.

11 Koyama K, Okamura T, Kawabe J, Nakata B, Hirakawa K, Chung YS, Ochi H, Yamada R: Diagnostic usefulness of FDG PET for pancreatic mass lesions. Ann Nucl Med 2001;15:217224.

12 Higashi T, Sakahara H, Torizuka T, Nakamoto $\mathrm{Y}$, Kanamori S, Hiraoka M, Imamura M, Nishimura Y, Tamaki N, Konishi J: Evaluation of intraoperative radiation therapy for unresectable pancreatic cancer with FDG PET. J Nucl Med 1999;40:1424-1433.

13 Humm JL, Rosenfeld A, Del Guerra A: From PET detectors to PET scanners. Eur J Nucl Med Mol Imaging 2003;30:1574-1597.

14 Heinrich S, Goerres GW, Schafer M, Sagmeister M, Bauerfeind P, Pestalozzi BC, Hany TF, von Schulthess GK, Clavien PA: Positron emission tomography/computed tomography influences on the management of resectable pancreatic cancer and its cost-effectiveness. Ann Surg 2005;242:235-243.

\section{Reply}

We appreciate the interest shown by Pedrazzoli and colleagues in the paper by Lytras et al. [1].

FDG-PET scans rely on the uptake of glucose by the targeted cells. The glucose transporter 1 (GLUT-1) is a member of the GLUT family of facilitative glucose transporters. Overexpression of GLUT-1 has been demonstrated in $88 \%$ of pancreatic cancer (in small numbers) and also in 50\% of benign tumours [2]. The association of GLUT-1 and tumour invasiveness has only been shown in vitro at the present time [3].

It is not quite true to say that less aggressive cancers may be FDG-PET scan falsenegative as even benign tumours can overexpress GLUT-1 [2]. The key issue is the overcalling of benign lesions to be cancer in the face of inflammation or benign disease [4].

The main differential diagnosis for these patients is an inflammatory mass due to chronic pancreatitis. For these patients the C-reactive protein, leukocyte count and alkaline phosphatase may be normal and therefore cannot be relied upon to rule out inflammatory causes. The serum CA 19-9 may be raised in these patients with inflammation, thus adding to the diagnostic diffculty [5].

There is indeed difficulty in interpreting FDG-PET scans due to different protocols and the effects of body weight and glucose metabolism [6]. Of those patients who had between 130 and $180 \mathrm{mg} / \mathrm{dl}$ glucose in our study (total of 11 out of 118 patients, or 9\%), 6 were malignant on PET scanning and 4 were non-malignant ( 1 was indeterminate).

The timing of the PET scan and acquisition in our study was $50 \mathrm{~min}$ (not $15 \mathrm{~min}$ as written in the paper), then continued for $40 \mathrm{~min}$. This was appropriate for our instrumentation.

SUVs are not appropriate when using gamma-camera PET.

The number of patients involved in this prospective study is large and therefore results from this study are valuable compared to studies of fewer patients with different instrumentation.

The study by Heinrich et al. [6] used a small number of patients and is therefore 
underpowered. Histological diagnosis was available in 52 patients only. It was claimed that PET-CT detected additional distant metastases in 5 and synchronous rectal cancer in 2 patients and that the findings changed the management in $16 \%$ of patients, with pancreatic cancer deemed resectable after routine staging $(\mathrm{p}=0.031)$. This study did not utilize contrast-enhanced multi-slice CT scan, which is widely regarded as the gold standard and therefore the conclusions are not valid, as these results could be completely reproducible using CECT scan only: a fact acknowledged by the authors themselves. This is the first report describing a coincidence between pancreatic cancer and rectal cancer of $4 \%$ and must therefore be treated with considerable caution. The study was not hypothesis driven and was without appropriate power calculations. The conclusions are not supported by the study because of poor design and an invalid comparison.
Advances in technology such as new generation PET-CT scanners and newer contrast agents such as $\left[{ }^{18} \mathrm{~F}\right] \mathrm{FLT}$ will need further assessment [7]. However, the study highlights the importance of an integrated approach between diagnostic and clinical teams for patient management.

Paula Ghaneh

John P. Neoptolemos

\section{References}

1 Lytras D, Connor S, Bosonnet L, Jayan R, Evans J, Hughes M, Garvey CJ, Ghaneh P, Sutton R, Vinjamuri S, Neoptolemos JP: Positron emission tomography does not add to computed tomography for the diagnosis and staging of pancreatic cancer. Dig Surg 2005;22:55-61; discussion 62 .

2 Higashi T, Tamaki N, Honda T, Torizuka T, Kimura T, Inokuma T, Ohshio G, Hosotani R, Imamura M, Konishi J: Expression of glucose transporters in human pancreatic tumors compared with increased FDG accumulation in PET study. J Nucl Med 1997;38:1337-1344.
3 Ito H, Duxbury M, Zinner MJ, Ashley SW, Whang EE: Glucose transporter-1 gene expression is associated with pancreatic cancer invasiveness and MMP-2 activity. Surgery 2004; 136:548-556.

4 Rasmussen I, Sorensen J, Langstrom B, Haglund $\mathrm{U}$ : Is positron emission tomography using ${ }^{18} \mathrm{~F}$-fluorodeoxyglucose and ${ }^{11} \mathrm{C}$-acetate valuable in diagnosing indeterminate pancreatic masses? Scand J Surg 2004;93:191197.

5 Furuya N, Kawa S, Hasebe O, Tokoo M, Mukawa K, Maejima S, Oguchi H: Comparative study of CA 242 and CA 19-9 in chronic pancreatitis. Br J Cancer 1996;73:372-376.

6 Heinrich S, Goerres GW, Schafer M, Sagmeister M, Bauerfeind P, Pestalozzi BC, Hany TF, von Schulthess GK, Clavien PA: Positron emission tomography/computed tomography influences on the management of resectable pancreatic cancer and its cost-effectiveness. Ann Surg 2005;242:235-243.

7 Been LB, Elsinga PH, de Vries J, Cobben DC, Jager PL, Hoekstra HJ, Suurmeijer AJ: Positron emission tomography in patients with breast cancer using ${ }^{18} \mathrm{~F}-3$ '-deoxy-3'-fluoro- $L$ thymidine $\left({ }^{18} \mathrm{~F}-\mathrm{FLT}\right)-$ a pilot study. Eur J Surg Oncol 2006;32:39-43. 